\title{
EFFECT OF SODIUM CASEINATE/CELLULOSE NANOCRYSTALS ADDITION ON THE PHYSICAL AND OXIDATIVE STABILITY OF RED PALM OLEIN-IN-WATER PICKERING EMULSIONS
}

\author{
SEE KIAT WONG ${ }^{1}$; CHIEN LYE CHEW ${ }^{1,2}$; JANARTHANAN SUPRAMANIAM ${ }^{1}$; BENG TI TEY ${ }^{1,3}$; \\ TIN WUI WONG ${ }^{4}$ and SIAH YING TANG ${ }^{1,3,5^{*}}$
}

\begin{abstract}
This work investigated the use of a dual biopolymer system containing cellulose nanocrystals (CNC) and sodium caseinate (SC) for red palm olein-in-water (O/W) Pickering emulsion stabilisation. The effect of CNC particle concentration at a constant amount of SC on emulsion properties was particularly studied. The resultant mixed biopolymer-based emulsions were characterised for droplet size distribution, zeta potential, creaming index and microstructure, as well as primary and secondary oxidation products by oxidation tests at $90^{\circ} \mathrm{C}$. Results showed that creaming stability was relatively high for SC/CNC-stabilised emulsions compared to emulsions prepared with SC alone. Increasing CNC concentration from $0.25 \%$ to $1.00 \%(w / v)$ resulted in a gradual decrease in emulsion droplet size with increased surface negative charges. Higher CNC content induced a marked reduction in the lipid oxidation of SC/CNC-stabilised emulsions. The mixed SC/CNC biopolymer significantly improved the carotene retention of emulsions during the accelerated oxidation test. Emulsions comprising 1.00\% SC and 1.00\% CNC presented the highest negative surface charge, lowest peroxide value (PV), p-anisidine value ( $p$-AV), free fatty acid (FFA) value, and total oxidation value (TOTOX). The use of CNC imparted beneficial effects on reducing lipid oxidation and enhancing the stability of palm-based O/W emulsions stabilised by SC.
\end{abstract}

Keywords: cellulose nanocrystals, oxidative stability, physical stability, Pickering emulsions, sodium caseinate.

Received: 17 March 2021; Accepted: 1 October 2021; Published online: 3 December 2021.

Chemical Engineering Discipline, School of Engineering, Monash University Malaysia, Jalan Lagoon Selatan,

Bandar Sunway, 47500 Subang Jaya, Selangor, Malaysia.

2 Sime Darby Research, R\&D Centre, Carey Island, Lot 2664, Jalan Pulau Carey, 42960 Carey Island, Selangor, Malaysia.

3 Advanced Engineering Platform, School of Engineering, Monash University Malaysia, Jalan Lagoon Selatan, Bandar Sunway, 47500 Subang Jaya, Selangor, Malaysia.

4 Non-Destructive Biomedical and Pharmaceutical Research Centre, Smart Manufacturing Research Institute, Universiti Teknologi MARA, 42300 Puncak Alam, Selangor, Malaysia.

5 Tropical Medicine and Biology Platform, School of Science, Monash University Malaysia, Jalan Lagoon Selatan, Bandar Sunway, 47500 Subang Jaya, Selangor, Malaysia.

* Corresponding author email: patrick.tang@monash.edu

\section{INTRODUCTION}

Lipid oxidation is when free radicals 'attack' and 'steal' electrons from lipid molecules, causing oxidative degradation of lipid. This could lead to the poor stability and shorter shelf-life of lipidcontaining emulsion products. It is an undesirable process that leads to adverse impacts on food products, lowering overall quality. Oxidative rancidity, nutrients denaturation and potential toxicity are some of the unfavourable outcomes caused by lipid oxidation (Jacobsen et al., 2013). Generally, oils and fats that contain long-chain polyunsaturated fatty acids are more vulnerable to oxidation during storage or heat treatment as they have multiple double bonds and reactive hydrogen atoms. Especially oil-in-water $(\mathrm{O} / \mathrm{W})$ emulsions 
are thermodynamically unstable systems that are more vulnerable to lipid oxidation because the oil globules have an overall higher interfacial area than bulk oils (Berton-Carabin et al., 2014). The larger specific surface area allows more oxidation reactions to occur, resulting in a faster lipid oxidation rate that decreases the stability of the food products (Hu et al., 2016).

Red palm olein contains a higher level of carotenes and antioxidants than traditional refined palm oil because it is only mildly processed, allowing it to retain the nutritional compounds (Bonnie Tay and Choo, 2000). Low et al. successfully fabricated red palm olein-in-water $(\mathrm{O} / \mathrm{W})$ Pickering emulsions with dual stimulus responses using magnetic cellulose nanocrystals (CNC) as the stabiliser (Low et al., 2017). Most recently, Wong et al. (2021) demonstrated the preparation of highly stable red palm olein-based Pickering emulsions using CNC-soy protein isolate nanoconjugates. Even though red palm olein possesses high antioxidant content, lipid oxidation is often unavoidable in the case of $\mathrm{O} / \mathrm{W}$ emulsions. Lipid oxidation is believed to occur at the $\mathrm{O} / \mathrm{W}$ interface (Liu et al., 2018), where reactive oxygen species are readily available. $\mathrm{LOOH}$ and aldehydes or ketones are generated as the primary and secondary oxidation products, respectively (Xu et al., 2017b). These molecules eventually generate dietary advanced lipid oxidation end-products, threatening human health when consumed (Cao et al., 2018). This challenges researchers to seek desirable ingredients to stabilise such a food emulsion system using surfactants and colloidal particles.

Synthetic surfactants such as sorbitan esters and their ethoxylates and sucrose esters are commonly used in forming food emulsions. Still, research has demonstrated that the accumulative use of surfactants could result in toxicity and carcinogenicity. Thus, selecting suitable emulsifiers in food applications is still limited due to their non-biocompatible properties (Ho et al., 2016). Recently, many efforts have been invested in using food-grade colloidal particles to stabilise foodbased emulsions. Incorporating colloidal particles to shield the oil and form a layer or multiple layers around the oil droplets can enhance its stability. The colloidal particles that are adsorbed irreversibly at the oil-water interface provide high stability to the emulsion as an energy barrier that effectively separates the two immiscible phases (Zoppe et al., 2012). This emulsion system is known as Pickering emulsion and has been widely used in biomedical, food and cosmetic products. Pickering emulsifiers have demonstrated a better stabilisation effect against coalescence of emulsified droplets, and some solid particles also possess additional properties such as antioxidants, antimicrobial and responsiveness to external stimulus (Ho et al., 2016).
Hence, selecting suitable food-grade solid particles to form an edible emulsion is crucial in producing products with desired properties and outstanding stability.

As one of the most promising and environmentally friendly particles, sodium caseinate (SC) has been utilised as a biopolymer emulsifier due to its lower cost, improved stabilisation and oxidation stability than other milk proteins (whey protein isolate, calcium caseinate and $\beta$-lactoglobulin) (Chang and Nickerson, 2018). However, proteins are vulnerable to changes in temperature, $\mathrm{pH}$ and ionic strength, which limit their applications, especially in the food industry (Hu et al., 2016). Hence, a secondary colloidal particle such as a polysaccharide may be introduced into the formulation to enhance the emulsion stability and reduce the oxidation rate.

CNC have attracted much attention as a foodgrade material source due to their abundant availability, biocompatibility, renewability, and flexibility with surface modification to increase their desired characteristics (Zoppe et al., 2012). $\mathrm{CNC}$ was commonly produced by sulphuric acid hydrolysis, which yields rod-like crystals with unique surface charges and mechanical properties. CNC has been considered an excellent Pickering stabiliser for food emulsion due to its non-toxicity, anti-oxidative properties, biodegradability and abundant supply (Low et al., 2019; Wong et al., 2021). CNC utilisation as a stabiliser in Pickering emulsion is expected to bring more advantages to the emulsion system. Studies have shown that the combination of proteins and polysaccharides as the stabiliser improved the oxidative stability and physical stability of emulsions formed ( $\mathrm{Li}$ et al., 2017; Xu et al., 2017a). Previous studies have shown that the SC/CNC-stabilised emulsions were formed due to the higher surface activity of SC and irreversibility of adsorption of CNC at pH 7 (Pindáková et al., 2019). However, the use of SC/CNC biopolymeric mixture has not been explored in greater depth for both physical and oxidative stability improvement of palm-oleinbased Pickering emulsions in the literature.

The present study aimed to investigate the addition of different $\mathrm{CNC}$ concentrations with $\mathrm{SC}$ on emulsion stabilisation processes. For this purpose, red palm $\mathrm{O} / \mathrm{W}$ Pickering emulsions were prepared and stabilised by SC solely or mixed with CNC particles. The influence of different $\mathrm{CNC}$ concentrations [from $0.25 \%$ to $1.00 \%$ $(\mathrm{w} / \mathrm{v})]$ at a fixed amount of SC $(1.00 \% \mathrm{w} / \mathrm{v})$ on emulsion physical and oxidative stability was investigated. The physical stability parameters such as creaming index, droplet size, zeta potential and microstructures of resultant emulsions were measured, and analysed. The overall oxidative stability of the encapsulated red palm olein was 
evaluated by determining the peroxide value $(\mathrm{PV}), \mathrm{p}$-anisidine value $(\mathrm{p}-\mathrm{Av})$, free fatty acid (FFA) value, total oxidation value (TOTOX), and carotene content via accelerated oxidation test at $90^{\circ} \mathrm{C}$.

\section{MATERIALS AND METHODS}

\section{Materials}

SC was purchased from Sigma Chemicals Co. (St. Loius, MO, USA). CNC (freeze-dried, $0.96 \mathrm{wt} \%$ sulphur content) were procured from the University of Maine, USA. Red palm superolein was acquired from Sime Darby Jomalina Sdn. Bhd., Malaysia. Ultrapure water $\left(18.2{\mathrm{M} \Omega \mathrm{cm}^{-1}}^{-1}\right.$ was obtained from the Milli-Q® Plus apparatus (Millipore, Billerica, USA). All chemicals used in this study were of analytical grade.

\section{Preparation of Olein-in-Water (O/W) Emulsions}

A series of emulsions were prepared using the ultrasonication method (all in weight proportion). Briefly, SC $(1.00 \% \mathrm{w} / \mathrm{v})$ was first dispersed in deionised water using a magnetic stirring apparatus at room temperature for $2 \mathrm{hr}$. The solution was stored overnight at $4^{\circ} \mathrm{C}$ before Pickering emulsion preparation. The continuous aqueous phase with four different $\mathrm{CNC}$ concentrations was prepared using CNC particles of $0.25 \%, 0.50 \%, 0.75 \%$ and $1.00 \%(\mathrm{w} / \mathrm{v})$ into the prepared SC solution followed by uniform mixing. The oil phase, namely palm olein (20\%), was gradually added into the resultant polysaccharide-protein mixtures and emulsified using ultrasonic horn $(20 \mathrm{kHz}, 50 \mathrm{~W}$ system, NexTgen ultrasonic platform, Sinaptec, France) at room temperature for $5 \mathrm{~min}$. The resultant emulsions were transferred to glass vials and stored at room temperature in the dark for further analysis. During the emulsion preparation, sodium azide of $0.02 \%(\mathrm{w} / \mathrm{v})$ was added to control microbial growth during storage. Emulsion stabilised by SC alone $(0 \%$ $\mathrm{CNC}$ ) was used as the control throughout the whole study.

\section{Characterisation of Biopolymers}

Particle size and zeta potential. The average particle size of SC, CNC and mixed SC / CNC samples were measured using dynamic light scattering (DLS) (Zetasizer Nano, Malvern Instruments, United Kingdom). The surface charge was measured in terms of zeta potential using the laser Doppler micro-electrophoresis technique (Zetasizer Nano, Malvern Instruments, United Kingdom) at $\mathrm{pH}$ 7.5 and $25^{\circ} \mathrm{C}$. Triplicates were conducted for each sample, and the results were averaged.
Morphology of particles. The size and morphology of SC, CNC and mixed SC/CNC samples were analysed using a field emission scanning electron microscope (FE-SEM) (Hitachi, SU8010, Japan) at $15 \mathrm{kV}$ in STEM mode. The samples were prepared by dispersing in deionised water and sonicated for $5 \mathrm{~min}$. Then, the samples were dipped onto a 300-mesh formvar carbon-coated copper grid. The copper grids were air-dried before viewing.

Water contact angle. The water contact angle was measured using a sessile drop method with a goniometer (Model 190, Rame-hart, USA). Briefly, microscope glass slides were coated with mixtures containing SC with different CNC concentrations by depositing the freshly sonicated suspension onto the clean substrates and dried at $50^{\circ} \mathrm{C}$ overnight. The water contact angle measurement was performed by placing a drop of water at five different points on the SC-CNC-coated thin film using a precision micro-syringe. Then, water contact angles were determined by applying the Laplace-Young fitting algorithm. The result was reported as the average of these five-point measurements.

\section{Characterisation of Pickering Emulsion}

Creaming index (CI). The emulsions were prepared, placed in vials hermetically, and stored upright at $25^{\circ} \mathrm{C}$. The $\mathrm{CI}$ was measured via visual inspection of the emulsion separation into an upper oil-rich layer, cream layer and a lower oil-depleted or serum layer at days 0 and 30 during storage. The $\mathrm{CI}$ was determined using the Equation (1):

$$
\mathrm{CI}(\%)=H_{C} / H_{T}
$$

where, $H_{c}=$ height of the cream layer and $H_{T}=$ total height of the emulsion.

Droplet size and zeta potential. The mean droplet size $\left(D_{4,3}\right)$ and size distribution of all samples were measured by static light scattering (Mastersizer 3000, Malvern Instrument, United Kingdom) equipped with a Hydro EV wet dispersion unit. Deionised water was used as the dispersant. The refractive index of palm olein and dispersant phase are 1.458 and 1.330, respectively. The droplet size of all the emulsion samples was measured in triplicate, and results were reported as volumeweighted mean diameter, $\mathrm{d}_{4,3}$. The zeta potential of all samples was analysed via laser Doppler microelectrophoresis technique (Zetasizer NanoZS 90, Malvern Instrument, United Kingdom). Each sample was diluted 100 times with deionised water before measurement. The result was reported as the average of three measurements. 
Microstructural analysis. The morphological structures of the emulsions were determined using an inverted optical microscope (Nikon Eclipse TS100, Nikon Instruments Inc., USA) at 20x magnification. A $10 \mu \mathrm{l}$ of each emulsion was placed on a glass, and then, a coverslip was carefully placed to prevent the trapping of air bubbles. The images were then captured using a charge-coupled device (CCD) camera.

Analysis of lipid oxidation in emulsions. The oxidative stability measurements of $\mathrm{PV}, p-\mathrm{AV}$, FFA, total oxidation (TOTOX) and carotene content were performed throughout five days of the accelerated oxidation study. The oil extraction method was adopted using a mixture of isopropanol and hexane $(1: 3, \mathrm{v} / \mathrm{v})$ to break the emulsions. The resultant solution was vortexed for $2 \mathrm{~min}$, and the organic layer was separated via centrifugation at $4000 \mathrm{rpm}$ for $20 \mathrm{~min}$, followed by rotary evaporation. The extracted oil (red palm olein) was collected and kept for subsequent analysis.

Primary oxidation products - peroxide value (PV). Lipid hydroperoxides (LOOH) were measured as primary oxidation products according to the American Oil Chemist's Society (AOCS) official methods, Cd 8b-90 (AOCS, 1997). Briefly, $3 \mathrm{~g}$ of oil sample was added to a mixture of $30 \mathrm{ml}$ glacial acetic acid/ chloroform (3:2 v/v). Subsequently, $0.5 \mathrm{ml}$ of saturated potassium iodide solution was added, and the resultant mixture was vortexed for $1 \mathrm{~min}$. A total of $30 \mathrm{ml}$ of deionised water was then added, followed by $0.5 \mathrm{ml}$ of a starch solution as the indicator. The final mixture was titrated against $0.01 \mathrm{~N}$ sodium thiosulphate until the indicator changed its colour from blue-black to colourless. The PV was determined using the Equation (2):

$$
\mathrm{PV}=\frac{(\mathrm{V} \times \mathrm{N}) \times 1000}{\mathrm{~W}}
$$

where, $\mathrm{V}=$ volume in $\mathrm{ml}$ of sodium thiosulphate solution used, $\mathrm{N}=$ normality of sodium thiosulphate solution, and $\mathrm{W}=$ weight in grams of the test portion. Measurements were carried out in triplicate.

Secondary oxidation products - p-anisidine value $(p-A V)$. Secondary oxidation products, namely aldehydes and ketones associated with oxidative rancidity were measured according to AOCS official methods, Cd 18-90 (AOCS, 1997). Briefly, $1 \mathrm{~g}$ of oil sample was added into a volumetric flask, and the volume was made up to the mark with iso-octane as the solvent. The absorbance was then measured using a UV-visible spectrophotometer (Varian Cary 50, USA) at $350 \mathrm{~nm}$ and used as blank. A $5 \mathrm{ml}$ of oil sample was added with $1 \mathrm{ml}$ of p-anisidine, and the resultant solution was mixed thoroughly. The absorbance of the sample treated with p-anisidine was recorded at $350 \mathrm{~nm}$ after $10 \mathrm{~min}$. The $\mathrm{p}-\mathrm{AV}$ was determined using the Equation (3):

$$
\mathrm{p}-\mathrm{AV}=\frac{100 \times \mathrm{Q} \times \mathrm{V} \times[1.2(\mathrm{As}-\mathrm{Ab})]}{\mathrm{W}}
$$

where, $A_{s}=$ absorbance of sample added with p-anisidine at $350 \mathrm{~nm}, \mathrm{~A}_{\mathrm{b}}=$ absorbance of the sample without p-anisidine at $350 \mathrm{~nm}, \mathrm{Q}=$ sample content in grams per millilitres $\left(Q=0.1 \mathrm{~g} \mathrm{ml}^{-1}\right)$ of the measured solution based on which the anisidine value is expressed, $\mathrm{V}=$ volume in grams per millilitres $(\mathrm{V}=25 \mathrm{ml})$ in which, the sample is dissolved, $1.2=$ correction factor for the dilution of the $5 \mathrm{ml}$ of the test solution with $1 \mathrm{ml}$ of the p-anisidine and $\mathrm{W}=$ weight in grams $(\mathrm{g})$ of the test portion.

\section{Free Fatty Acid (FFA)}

The acidity test was conducted according to AOCS official methods, Ca 5a-40 (AOCS, 1997). Briefly, about $5-10 \mathrm{~g}$ of oil sample were added into $50 \mathrm{ml}$ of heated isopropanol: phenolphthalein (100:1, v/v\%). A $0.1 \mathrm{M}$ potassium hydroxide was added dropwise into the resultant mixture until a faint but permanent pink colour was obtained. The neutralised mixture was added into the 250 $\mathrm{ml}$ conical flask and titrated using $0.1 \mathrm{M}$ potassium hydroxide until a permanent faint pink colour was obtained. The FFA was then determined using the Equation (4):

$$
\text { FFA }(\text { palmitic acid })=\frac{25.6 \times \mathrm{M} \times \mathrm{V}}{\mathrm{W}}
$$

where $\mathrm{M}=$ molarity of potassium hydroxide solution, $\mathrm{V}=$ volume in $\mathrm{ml}$ of potassium hydroxide solution used, and $\mathrm{W}=$ weight in grams ( $\mathrm{g}$ ) of the test portion.

Total oxidation value (TOTOX) and carotene content. The TOTOX and carotene content are essential measurements for oxidation study in palm olein. Generally, the lower the TOTOX value, the better the quality of the oil. Carotene content is another key parameter in protecting the oil quality, given its pro-antioxidant property. The determination of both TOTOX and carotene content was performed according to Malaysian Palm Oil Board (MPOB) test methods, p2.14 and p2.6 (Ainie et al., 2004), respectively. Briefly, $0.1 \mathrm{~g}$ of oil sample was added into a volumetric flask, and the volume was made up to the mark with iso-octane as the solvent. The TOTOX value and carotene value were calculated using the Equation (5) and Equation (6), respectively: 


$$
\text { TOTOX }=\text { Corrected } \mathrm{A}_{233}+\text { Corrected } \mathrm{A}_{446}
$$

where, Corrected $\mathrm{A}_{233}=\mathrm{A}_{233}-\frac{0.06}{383} \times$ carotene content in $\mathrm{mg} / \mathrm{kg}$ and Corrected $\mathrm{A}_{446}=\mathrm{A}_{446}-\frac{0.06}{383} \times$ carotene content in $\mathrm{mg} / \mathrm{kg}$

$$
\text { Carotene }(\mathrm{mg} / \mathrm{kg})=\frac{383 \times A}{l \times C}
$$

where $383=$ the extinction coefficient for carotenoids, $\mathrm{A}=$ absorbance of the sample at $269 \mathrm{~nm}, 1$ = path length of the cell (in $\mathrm{cm}$ ), and $\mathrm{C}=$ concentration of sample used for measurement (in g per $100 \mathrm{ml}$ ).

Statistical analysis. All the results were expressed as the mean value \pm standard deviation of the measurements. Analysis of variance (ANOVA) was conducted using Prism software, and the differences were considered statistically significant when $p<0.05$.

\section{RESULTS AND DISCUSSION}

\section{Characterisation of SC, CNC and SC/CNC Mixture}

Particle size is an essential characteristic for Pickering emulsion stabiliser, as it directly affects the emulsion droplet size. Smaller particles can assemble quickly around the oil-water interfaces to facilitate the formation of smaller oil droplets (Song et al., 2020). SC exhibited the largest average particle size (Figure 1a) at $334.1 \pm 20.6 \mathrm{~nm}$, which decreased to $256.9 \pm 35.4 \mathrm{~nm}$ after the addition of $\mathrm{CNC}$ at a 1:1 ratio $(\mathrm{w} / \mathrm{w})$. The reduction in particle size could be due to the presence of smaller CNC particles $(127.4 \pm 12.1 \mathrm{~nm})$, contributing to a shift in particle size distribution to a lower region (smaller size) in the DLS analysis.

The microstructure of SC, CNC and mixed $\mathrm{SC} / \mathrm{CNC}$ was evaluated by scanning transmission electron microscopy (STEM), as shown in Figures 1b, $1 c$ and $1 d$. Micrographs of SC particles alone showed a mixture of non-uniform aggregated particles with some spherical globular proteins. The particle size obtained from STEM analysis displayed a wide range of sizes, with the smallest size at $<100 \mathrm{~nm}$ and the biggest size (aggregates) at $>300 \mathrm{~nm}$. However, the results obtained by STEM were not in good agreement with the results of our DLS analysis. The observed difference in particle sizes could be due to the occurrence of aggregation of SC particles when dried from a monodispersed suspension, which rendered a larger average particle size of around $334 \mathrm{~nm}$. Nevertheless, the results agreed with other reported values between 50-600 nm (Francis et al., 2019; Le et al., 2008). On the other hand, CNC particles showed needle-like structures with a length of $100-150 \mathrm{~nm}$ and a diameter of $<10 \mathrm{~nm}$.
The mixed SC/CNC micrograph displayed two distinct shaped particles with the larger globular particles as SC and the smaller needle-like particles as CNC. No morphological or structural changes of SC particles were observed upon the addition of CNC.

The surface charge is another critical indicator for measuring the stability of emulsion droplets. The mixed SC/CNC biopolymer possessed good stability with a zeta potential of $-37.7 \pm 2.5$ $\mathrm{mV}$, whereas the recorded zeta potential of SC alone was $-19.1 \pm 0.8 \mathrm{mV}$ at $\mathrm{pH}$ 7.5. SC has an isoelectric constant (pI) of 4.6, which will exist in its anionic form at a $\mathrm{pH}$ value greater than its pI (Zinoviadou et al., 2012). Zeta potential of $\pm 30 \mathrm{mV}$ is considered the borderline for good colloidal stability (Luo et al., 2013). The addition of a more negatively charged species (CNC particles) increased the overall charges of the mixed biopolymer system, contributing to greater electrostatic repulsion when used as an emulsion stabiliser in combination.

To characterise the wettability of SC and mixed SC/CNC biopolymer with different CNC concentrations, contact angle measurements were investigated on thin films coated with a biopolymeric emulsifier. As shown in Figure 1e, the water contact angle of SC alone was $79.69^{\circ} \pm 2.14^{\circ}$ at room temperature. After the addition of $\mathrm{CNC}$, the contact angle decreased with increased CNC concentration due to the hydrophilic nature of $\mathrm{CNC}$. There was no statistically significant difference in the contact angle of samples containing $0.25 \%$ to $0.75 \%$ of $\mathrm{CNC}$, indicating incomplete surface coverage of CNC in the film. However, at $1 \% \mathrm{CNC}$, the contact angle achieved was $68.57^{\circ} \pm 2.24^{\circ}$. The wettability of these particle coated films was higher, with a slightly more hydrophilic surface. The data agreed with another study as reported elsewhere (Sukyai et al., 2018). Based on the literature, the contact angle at $15^{\circ}<\theta<90^{\circ}$ is suitable to form $\mathrm{O} / \mathrm{W}$ emulsions, where the contact angle of the SC / CNC mixture falls within the optimum range (Low et al., 2020; Ortiz et al., 2020). The use of mixed SC/ CNC particles with slightly lower contact angle did not lead to poor emulsion stability, as evidenced by our droplet stability study as shown in Figure 4. It has been well documented that particles with greater hydrophilicity will promote the formation of $\mathrm{O} / \mathrm{W}$ emulsions and vice versa (Clegg et al., 2016; Jeon and Hong, 2014). Earlier studies also reported that utilising a blend of emulsifiers can produce emulsions with greater stability than using a single emulsifier (Chen et al., 2018; Liu et al., 2012). The mixed SC/CNC was envisaged to demonstrate amphiphilic property, with SC particles preferentially wetted by the hydrophobic oil phase of the emulsion and the hydrophilic CNC particles by the aqueous phase. 
(a)
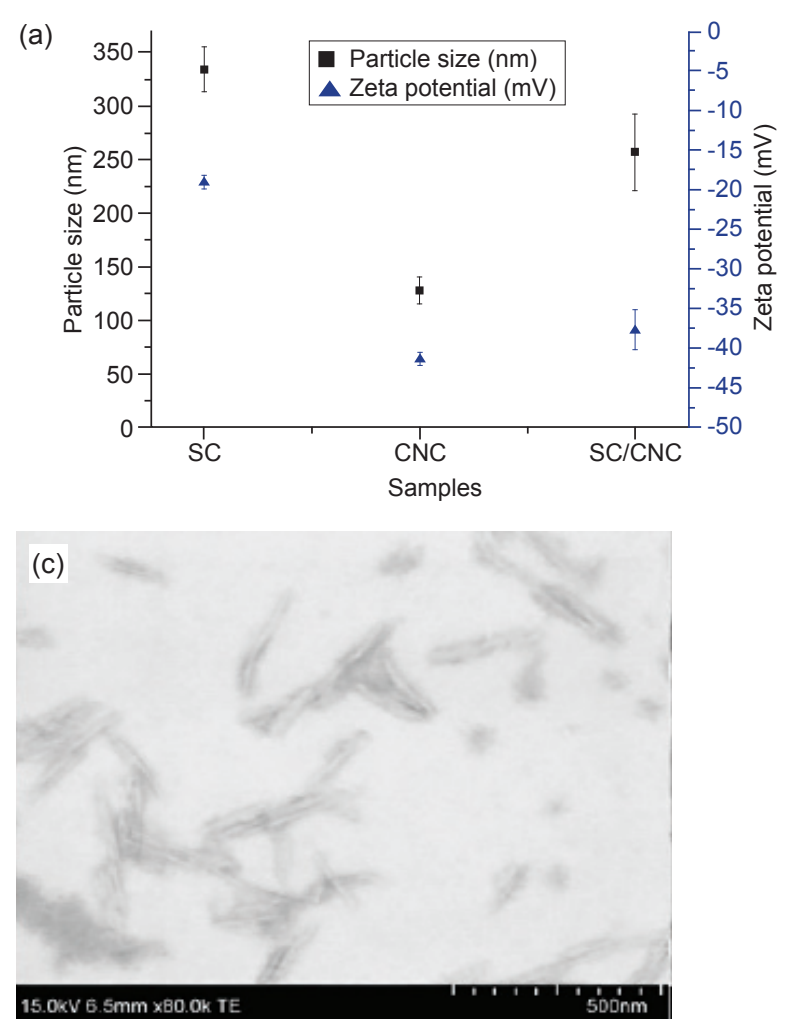
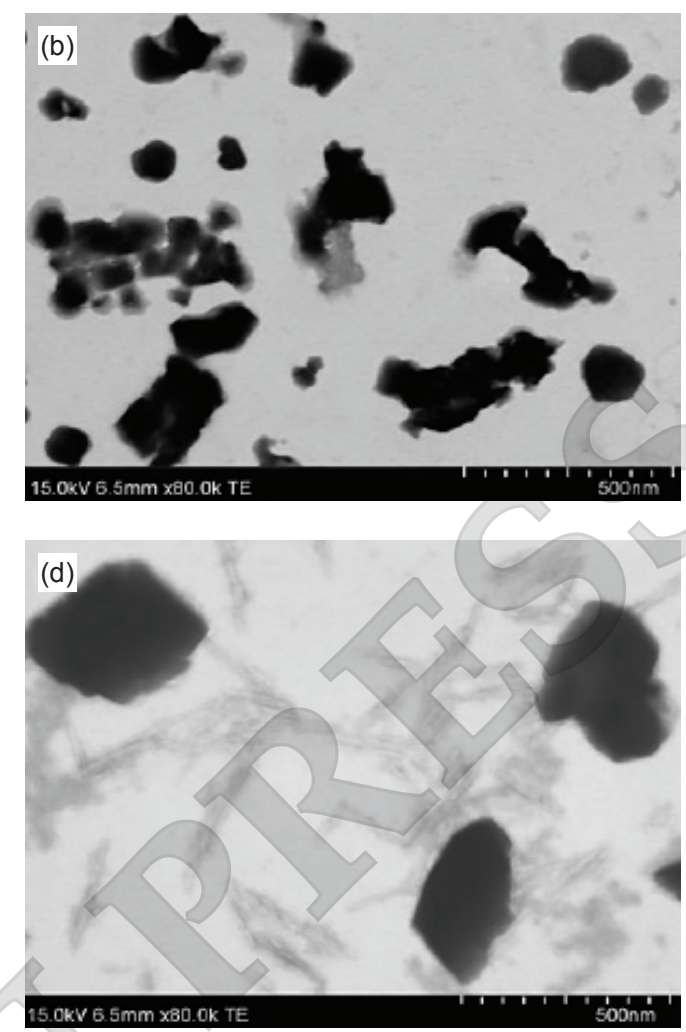

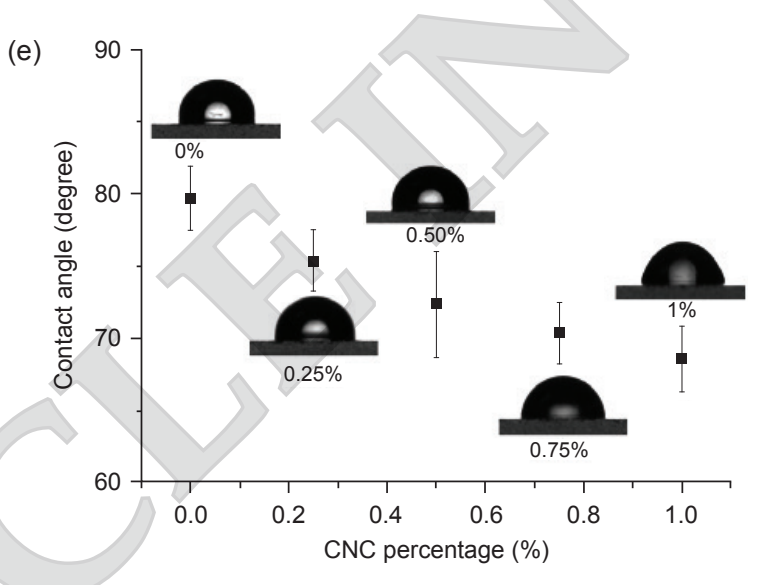

Figure 1. (a) Average particle size, zeta potential and micrographs of (b) SC, (c) CNC, (d) mixed SC/CNC, and (e) water contact angle of the aqueous solution containing $1.00 \%(w / v) S C$ and different CNC concentrations.

\section{Effect of CNC Content on Emulsion Stability, Particle Size and Zeta Potential}

The stability of droplets in emulsions is generally conferred by a charged interface, which generates a strong electrostatic repulsion. These electrical properties of the interfacial layer are due to the presence of ionic groups (such as carboxyl, sulphate or phosphate groups) on the surface of the emulsifiers (McClements, 2015). Many foodgrade amphiphilic polysaccharides (e.g. modified cellulose, gum Arabic, and modified starch) are negatively charged. A combination of biopolymer emulsifiers can be applied to modulate the required electrical characteristics of emulsion droplets in different emulsion systems.
Emulsion stability was enhanced with the addition of $\mathrm{CNC}$ with $\mathrm{SC}$, as shown in Figure 2. The maximum creaming indexes obtained for $0 \% \mathrm{CNC}$ (contained SC alone) and formulation contained $1.00 \%$ CNC were $36.6 \%$ and $19.8 \%$, respectively, at day 30 , showing greater stability with $1.00 \%$ CNC as a reinforced stabiliser. The results demonstrated a lowered creaming index of the emulsions with increased CNC concentration. This can be deduced by the more robust three-dimensional network formed between droplets by CNC particles, limiting the mobility of oil droplets and preventing aggregations (Hu et al., 2016). Phase separation occurred by migrating larger particles to the top of the vial because they contained a higher volume of less dense oil. In comparison, the smaller particles 
remained at the lower phase of the vial. It should be noted that the lower phase of the emulsions remained cloudy and opaque, with no visible phase separation, suggesting that the emulsion is stable throughout the 30-days storage. Research has shown that the more transparent and clearer the emulsion layer, the higher the degree of droplets flocculation and coalescence could have occurred (Manoj et al., 1998).

The $\mathrm{D}_{4,3}$ of emulsions is shown in Figure $3 a$. There is a significant reduction between the average size of oil droplets stabilised by SC alone and 1.00\% $\mathrm{CNC}$ with SC on the first day after the preparation of the emulsions. The average size of the emulsion droplets stabilised by SC alone $(0 \% \mathrm{CNC})$ was $\sim 68 \%$ bigger than oil droplets stabilised by mixed $1.00 \% \mathrm{SC} / \mathrm{CNC}$. It was noted that there was a reduction of average droplet size with the addition of $0.25 \%-1.00 \%$ of CNC compared to $0 \% \mathrm{CNC}$ on the day of preparation. However, no significant difference was observed in the average sizes of emulsions stabilised with all CNC concentrations at day 30. Storage stability study showed that the $\mathrm{D}_{4,3}$ obtained for $0 \%$ CNC elevated from $12.70 \pm 2.75$ $\mu \mathrm{m}$ to $17.43 \pm 2.57 \mu \mathrm{m}$ (Figure $3 a$ ) over 30-days at room temperature. The particle size distribution showed a bimodal distribution where the second small peak has shifted to the right over the storage period, indicating coalescence of droplets into a larger one. From the microscopy images in Figure 4 , the oil droplets stabilised by SC alone tended to aggregate into larger droplets, which was not found in the oil droplets stabilised by the mixed SC/CNC biopolymer. It was reported that the osmotic effect associated with the non-adsorbed casein molecules increased the attractive forces between the oil droplets, which accelerated droplets aggregation and coalescence rate of emulsions (Wang et al., 2018).

(a)

Day 0

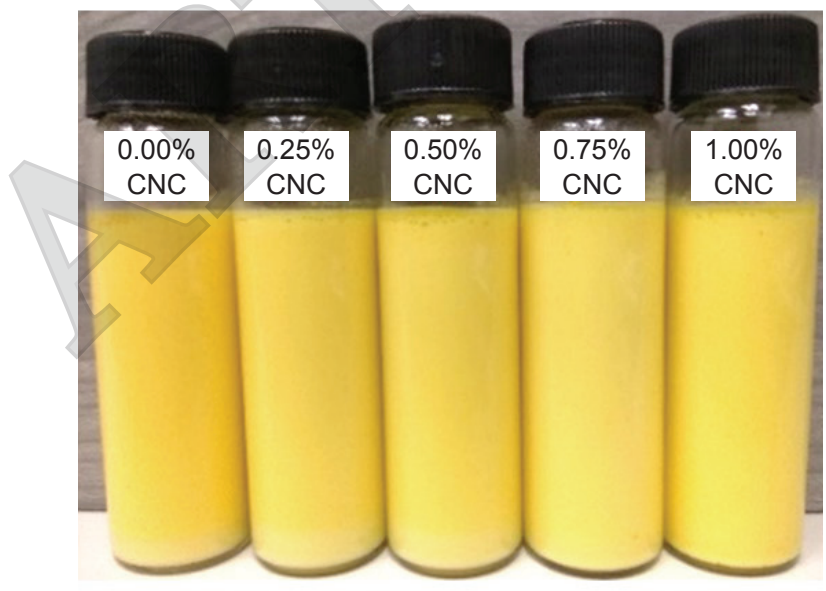

For formulation with added $1.00 \% \mathrm{CNC}$, the $\mathrm{D}_{4,3}$ remained constant around $4.12 \pm 0.32 \mu \mathrm{m}$ throughout the entire storage period with similar particle size distribution (Figure 4). The $\mathrm{D}_{4,3}$ of SC/CNC-stabilised emulsions was generally smaller than the emulsion containing SC alone. The difference in droplet diameter could be due to the higher volume of particles present during the emulsification process. More particles are available to absorb at the oil droplets interface, thus, forming smaller Pickering emulsion droplets. More colloidal particles are available to bind onto the oil and water interface during the emulsification process. Further aggregation was prevented presumably by steric repulsion and electrostatic forces by the absorbed particles (Guzey and McClements, 2006). Therefore, the SC/CNC-stabilised emulsions displayed better stability throughout the 30 -days storage with minute changes in the $\mathrm{D}_{4,3}$.

As depicted in Figure $3 b$, the $\zeta$-potential of Pickering emulsions stabilised by SC alone was lower than the other formulations that contained different CNC concentrations. The $\zeta$-potential of emulsion with $0 \% \mathrm{CNC}$ decreased from $-37.5 \mathrm{mV}$ to -32.7 $\mathrm{mV}$ over 30 -days storage at room temperature, showing some destabilisation of droplets when SC alone was used as the stabiliser. In contrast, the $\zeta$-potential of the formulation containing $1.00 \%$ CNC was kept in the range of $-50.0 \mathrm{mV}$ to $-53.0 \mathrm{mV}$ throughout 30-days storage. These results indicated that the addition of CNC as a reinforced emulsifier increased the negative charges on the surface of the emulsion droplets, which consequently induced greater electrostatic repulsion between oil droplets to prevent flocculation and coalescence ( $\mathrm{Xu}$ et al., 2017a). The high negatively charged surface of the SC/CNC-stabilised emulsion droplets corresponded to the constant $\mathrm{D}_{4,3}$ throughout the 30-days storage as presented above.

(b)

Day 30

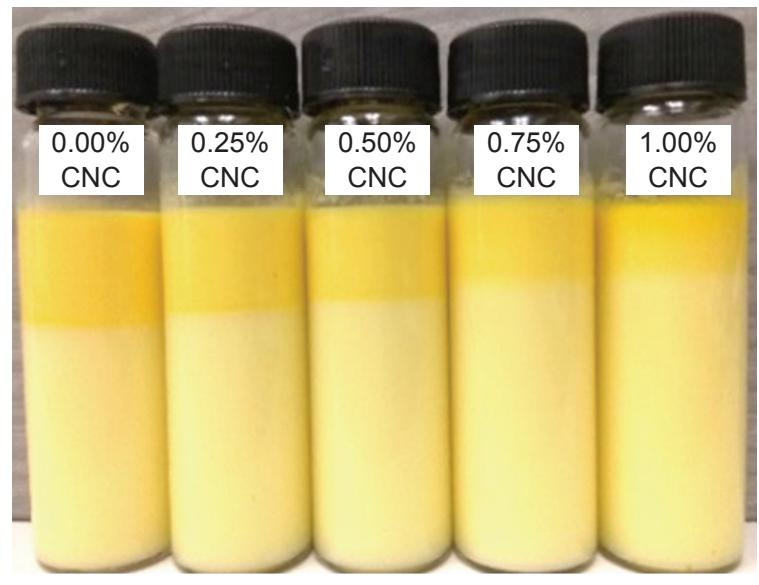

Figure 2. Creaming stability of $\mathrm{O} / \mathrm{W}$ emulsion $(20 / 80, v / v)$ with the aqueous phase containing $1.00 \%(w / v)$ of SC and different CNC concentrations at ( $a$ ) day 0 and $(b)$ day 30. 

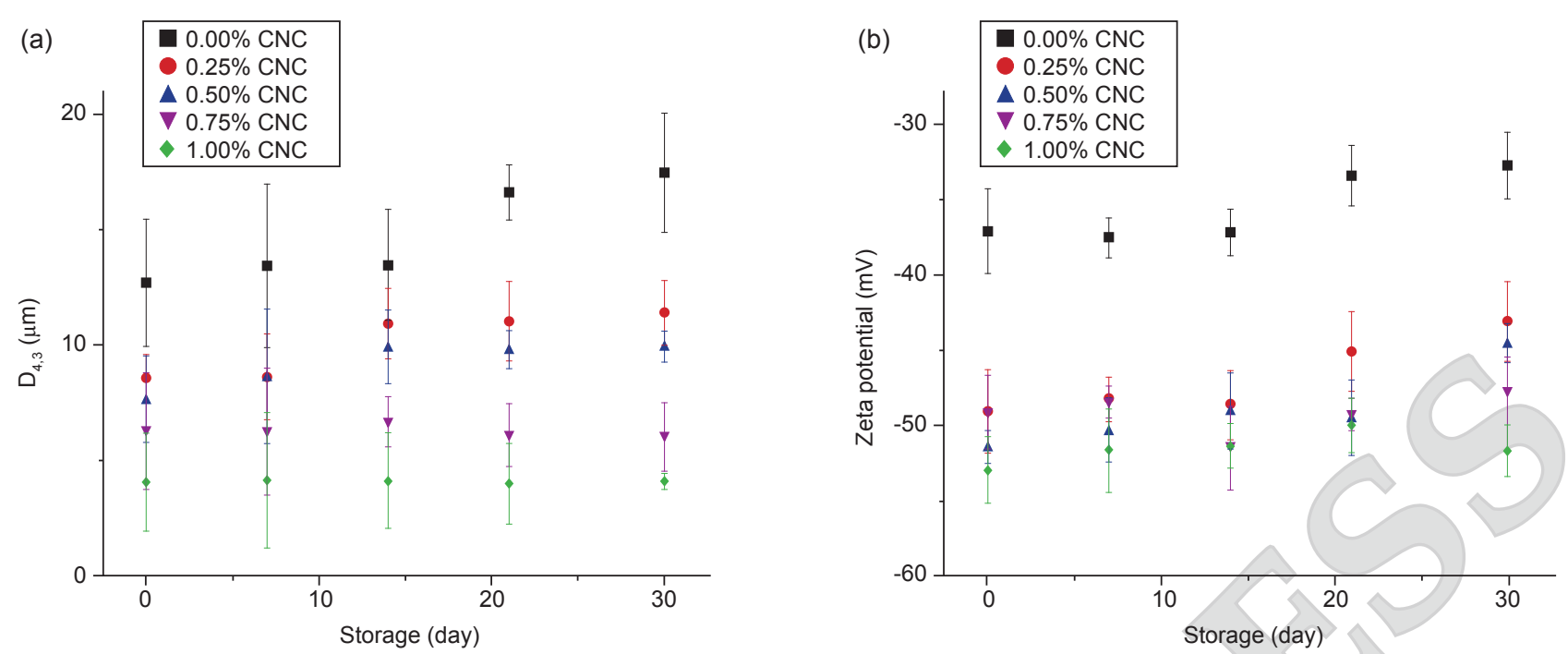

Figure 3. (a) Mean droplet size $\left(D_{4,3}\right)$ and $(b)$ zeta potential of $\mathrm{O} / \mathrm{W}$ emulsion $(20 / 80, v / v)$ with the aqueous phase containing $1.00 \%$ (w/v) of SC and different $C N C$ concentrations as a function of storage time at $25^{\circ} \mathrm{C}$. Data represent means $(n=3)$ with standard deviations (error bars).

\section{Influence of CNC Content on Lipid Hydroperoxide and p-Anisidine Value (p-AV)}

The effect of different CNC concentrations on the oxidative stability of the $\mathrm{O} / \mathrm{W}$ emulsions was assessed by measuring the PV and p-AV. PV and $\mathrm{p}-\mathrm{AV}$ are used to calculate the estimation of primary and secondary oxidation of lipid, respectively. The comparison was made between the control group ( $0 \% \mathrm{CNC}$ or containing SC alone) and the formulations containing different $\mathrm{CNC}$ concentrations. As depicted in Figure 5a, the PV content in $0 \% \mathrm{CNC}$ and formulation contained $1.00 \%$ CNC, which has the highest content of CNC was approximately 1.307 and 1.310 meq $\mathrm{kg}^{-1}$ oil at day 0 , and increased gradually with time to reach 38.25 and 27.79 meq $\mathrm{kg}^{-1}$ oil, respectively, after five days of accelerated oven testing at $90^{\circ} \mathrm{C}$. By contrast, the amount of PV generated in SC/CNC-stabilised emulsions was significantly lower by $27 \% \quad(p<0.05)$ than emulsions stabilised by SC alone, suggesting they were oxidised more slowly. The results also demonstrated that the oxidation trend of the emulsion was influenced by the concentration of CNC added, where an increase in CNC concentration generally lowered the generation of $\mathrm{LOOH}$.

Similar results were observed in terms of secondary oxidation products as depicted in Figure 5b, the content of p-AV for $0 \% \mathrm{CNC}$ and formulation contained $1.00 \% \mathrm{CNC}$ was 3.180 and 3.147 at day 0 , respectively. Then, the value raised to 4.581 and 3.698, respectively, after five days of accelerated testing. This revealed that the addition of CNC in forming emulsions could effectively reduce lipid oxidation, especially during secondary oxidation. The trend for developing $\mathrm{LOOH}$ and p-anisidine was similar for all the formulations containing mixed SC/CNC and $0 \% \mathrm{CNC}$ during day 1 to day 4 of incubation. However, during the fifth day of incubation, the $\mathrm{p}-\mathrm{AV}$ of the $0 \%$ $\mathrm{CNC}$ increased tremendously compared to other formulations. The rapid rise in $\mathrm{p}-\mathrm{AV}$ that occurred later than that of $\mathrm{LOOH}$ could be explained as the primary oxidation products must decompose before forming the secondary oxidation products since the hydroperoxides are not stable at high temperature (Chew et al., 2021). These results suggested that the SC/CNC-stabilised emulsions have a better antioxidant property than the formulation that contained SC alone. The results agreed with those reported elsewhere using a mix of polysaccharide and protein in stabilising $\mathrm{O} / \mathrm{W}$ emulsion (Qiu et al., 2015; Zeng et al., 2017).

Lipid oxidation usually occurs more rapidly at the oil and water interface contact region in a biphasic system than bulk oil. In a biphasic system, the chain reaction of lipid peroxidation can be initiated more rapidly due to the close contact of pro-oxidants in the aqueous phase with the oil droplets (Lomova et al., 2010). When a higher amount of solid particle emulsifiers is added, as in the case of increasing CNC concentration $(0.25 \%-1.00 \%)$, emulsions are stabilised by droplet rich network surrounded by the solid particle emulsifiers which irreversibly adsorbed to oilwater interface (Zoppe et al., 2012). This resulted in reduced lipid oxidation as displayed by lower PV and p-AV values. The colloid particles formed an energy barrier around the oil droplets which effectively blocked the highly reactive free radicals, as well as blocking the decomposition of $\mathrm{LOOH}$ into alkoxyl ( $\left.\mathrm{LO}^{-}\right)$and peroxyl ( $\mathrm{LOO}^{-}$) radicals. Furthermore, lipid oxidation can be further retarded by reducing the activity of free radicals in accepting hydrogen from unsaturated fatty acids to 


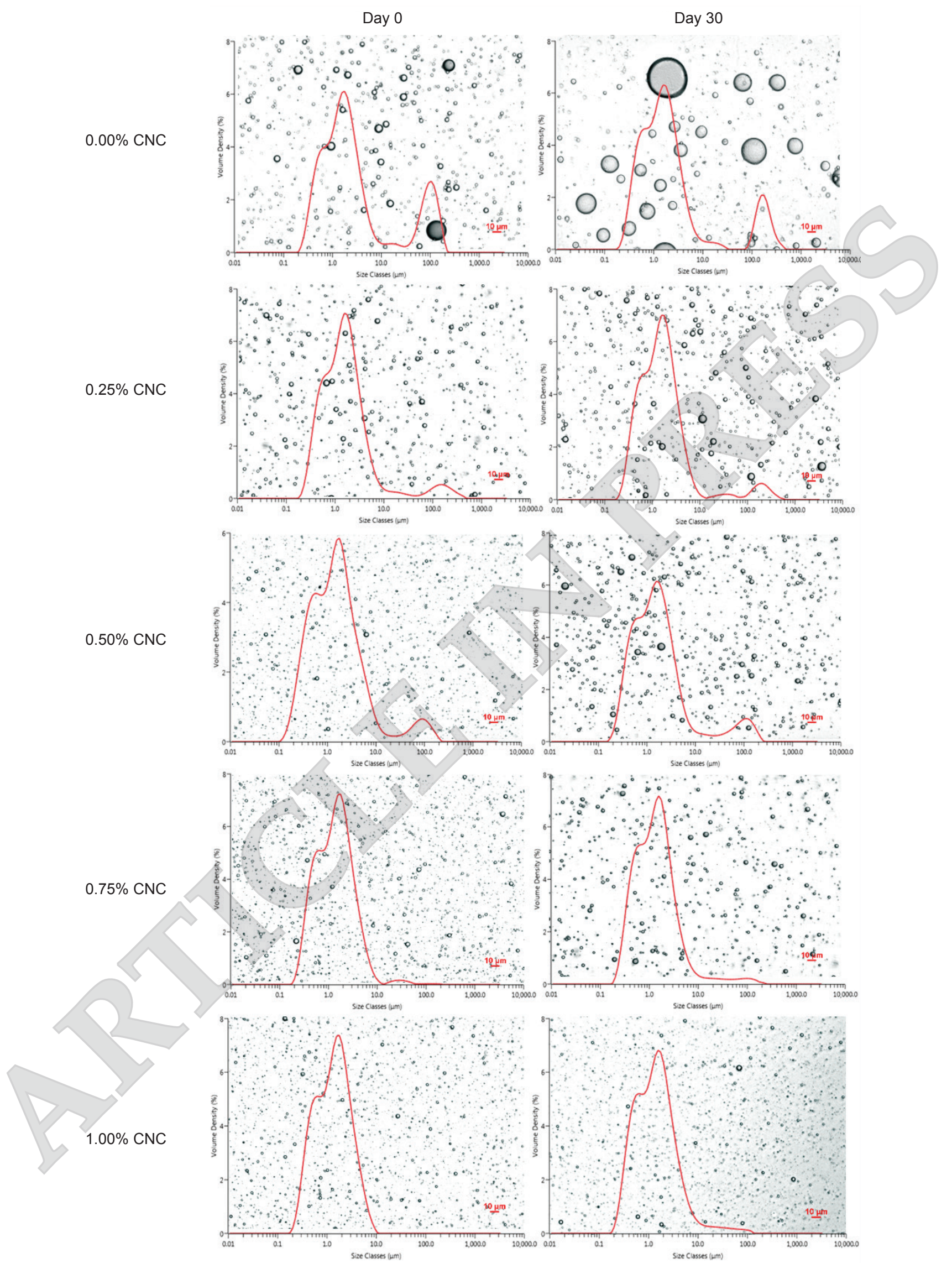

Figure 4. Optical micrographs of O/W emulsion $(20 / 80, v / v)$ with the aqueous phase containing $1.00 \%(w / v)$ of SC and different CNC concentrations on day 0 and day 30. Droplet size distributions of respective emulsions determined by static light scattering are superimposed on the micrographs. The bar length represents $10 \mu \mathrm{m}$. 
produce more free radicals (Chityala et al., 2016). All these possible mechanisms could be used to explain the slower rate for the formation of $\mathrm{p}-\mathrm{AV}$ content as the secondary oxidation products when the rate of primary lipid oxidation got reduced.

\section{Effect of CNC Content on FFA, TOTOX and Carotene Content}

Oil acidity testing was carried out to determine the amount of FFA produced by the hydrolysis of oils during the storage period. It is well known that FFA, diacylglycerol (DAG) and monoacylglycerol (MAG) are made from the hydrolysis of oils and fats, and this acid value is commonly used to predict the oxidative stability of vegetable oil (Yodkaew et al., 2017). As depicted in Figure 5c, after five days of accelerated storage, the FFA value for $0 \% \mathrm{CNC}$ and formulation contained $1.00 \%$ CNC increased from 0.0583 to 0.1820 and 0.0583 to 0.1300 , respectively. The FFA value of $0 \% \mathrm{CNC}$ was $\sim 29 \%$ more than the formulation stabilised with a mixture of $1.00 \%$ CNC. A smaller FFA value gives better oil quality as most of the oil molecules remained as the original TAG arrangement without being degraded. The results showed that adding $1.00 \% \mathrm{CNC}$ as the reinforced stabiliser could form a more stable emulsion against hydrolysis.

To further comprehend the rate of lipid oxidation, the TOTOX was calculated to estimate the oxidation deterioration of lipids. The TOTOX value is defined as a mathematical prediction of oxidative stability. It represents the sum of primary and secondary oxidation products, which correlates to oil deterioration (Pereira de Abreu et al., 2010). As depicted in Figure $5 d$, over the five days of accelerated testing, the TOTOX value for $0 \% \mathrm{CNC}$ and formulation contained $1.00 \%$ CNC increased from 1.272 to 4.293 and 1.286 to 3.178 , respectively. Formulation with a higher CNC concentration displayed a significantly lowered TOTOX value than the $0 \% \mathrm{CNC}(p<0.01)$, suggesting that the presence of SC/CNC mixtures are effective in inhibiting lipid oxidation in emulsions. These results were similar to the previous oxidation tests ( $\mathrm{PV}$ and $\mathrm{p}-\mathrm{AV}$ ), where the formulation contained $1.00 \%$ CNC exhibited the lowest rate of lipid oxidation compared with the other formulations. It was deduced that the lower the TOTOX value, the better the quality of the oil (Moigradean et al., 2012).

Carotenoids such as $\beta$-carotene serve as a biological antioxidant and a good source of vitamin A (Ferreira et al., 2016). The carotene originally found in red palm olein could be used as the first-line defence against lipid oxidation due to the available natural antioxidant. As depicted in Figure 5e, the amount of carotene available in red palm olein was approximately $460 \mathrm{mg} \mathrm{kg}^{-1}$ at day 0 . The value decreased significantly $(p<0.05)$ to $329 \mathrm{mg} \mathrm{kg}^{-1}$ for $0 \% \mathrm{CNC}$ as compared with formulation contained $1.00 \% \mathrm{CNC}$ which only decreased to $401 \mathrm{mg} \mathrm{kg}^{-1}$. The visual observation for the red colour of the extracted palm oil obtained decreased, showing that the carotene content reduced over the storage period.

Overall, the results suggested that the emulsion stability against lipid oxidation increased in the following order: $0 \% \mathrm{CNC}<0.25 \% \mathrm{CNC}<0.50 \%$ $\mathrm{CNC}<0.75 \% \mathrm{CNC}<1.00 \% \mathrm{CNC}$. This finding demonstrated where an increased concentration of polysaccharides enhanced overall emulsion stability and lower lipid oxidation rate. This is because formulations containing SC as an emulsion stabiliser were reported to form a stiff viscoelastic interfacial film with antioxidant activities such as free radical scavenging and reduced abilities (Cheetangdee and Benjakul, 2015). On the other hand, the addition of CNC into SC-based emulsions displayed better physical properties due to their highly crystalline nano and rigid rod-like structure, which could form a dense cellulose chain packed together with strong inter- and intramolecular hydrogen bonds (Grishkewich et al., 2017; Svagan et al., 2016) when used as a stabiliser in forming Pickering emulsion. Hence, SC reinforced with $\mathrm{CNC}$ as a food-grade stabiliser in forming Pickering emulsions could enhance oxidative stability. At the highest concentration of CNC $(1.00 \%)$, the rate of lipid oxidation was much lower than other formulations.

Schematic representation of possible droplet stabilisation mechanisms in emulsions prepared using SC/CNC mixture is depicted in Figure 6. When the hydrophilic CNC was added as a secondary stabiliser into the hydrophobic SC, the resultant $\mathrm{SC} / \mathrm{CNC}$ mixture with higher amphiphilic character could improve the wetting characteristics of the particles and facilitate effective partitioning at the $\mathrm{O} / \mathrm{W}$ interface, thus, rendering the emulsions greater physical and oxidative stability (Yokota et al., 2019). It was postulated that the palm-olein based emulsions were stabilised by mixtures of SC and CNC through mixed possible processes of adsorption, complexation and layerby-layer formation at the oil-water interface under the influence of the ultrasound field. It was also suggested that polysaccharides could be distributed on the surface of the droplets and the surrounding aqueous phase, thus, restricting the aggregation of oil droplets. Moreover, the anionic polysaccharide (contained surface hydroxyl and sulphate groups) with negatively surface charged could easily repel each other, which would keep the droplets further away from each other $(\mathrm{Xu}$ et al., 2017a). All these factors are essential in forming stable O/W Pickering emulsion as well as in lipid oxidation inhibition. 
(a)

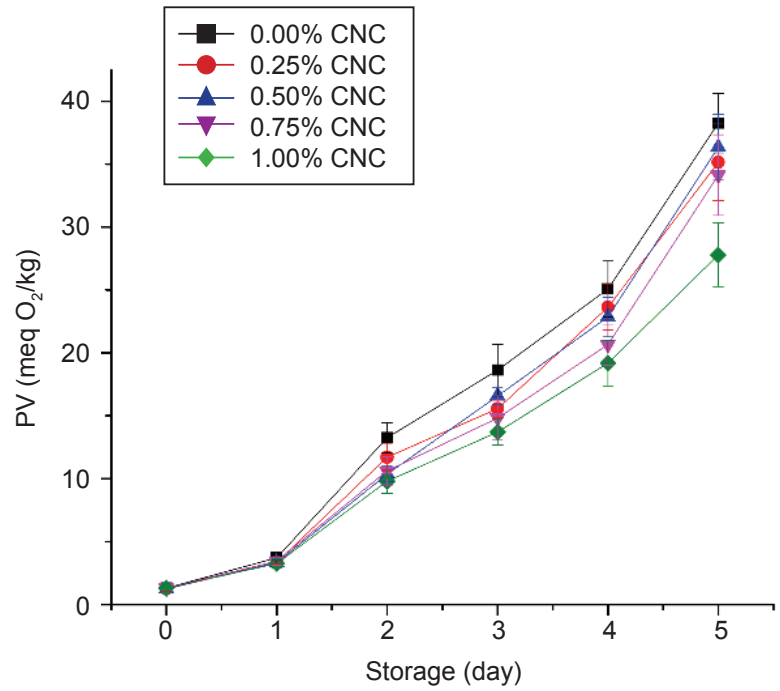

(c)

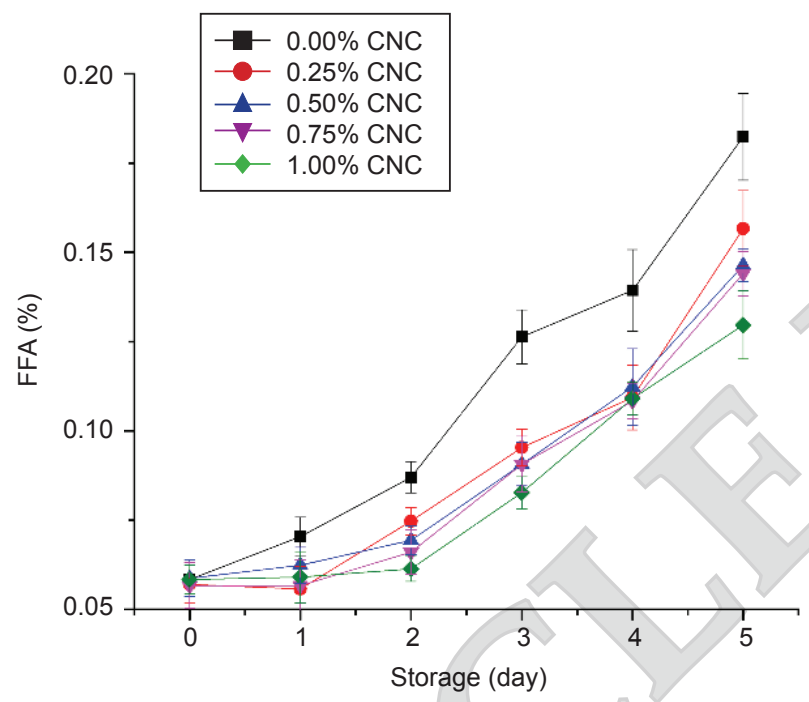

(b)

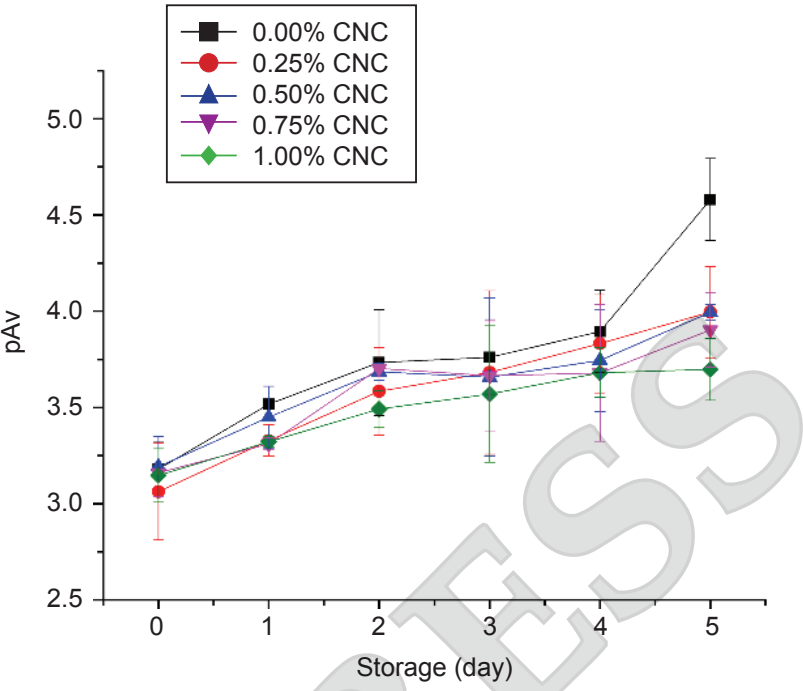

(d)

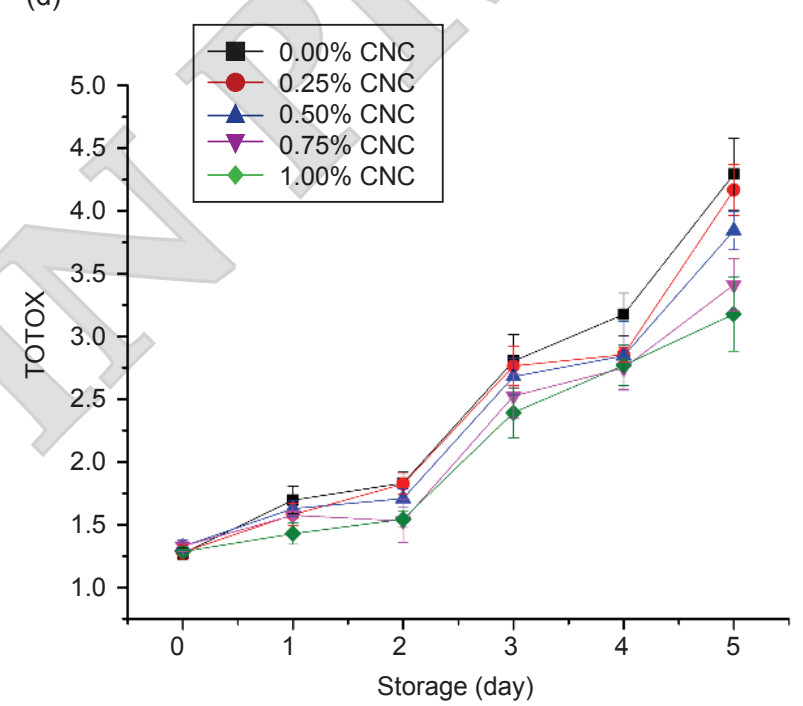

(e)

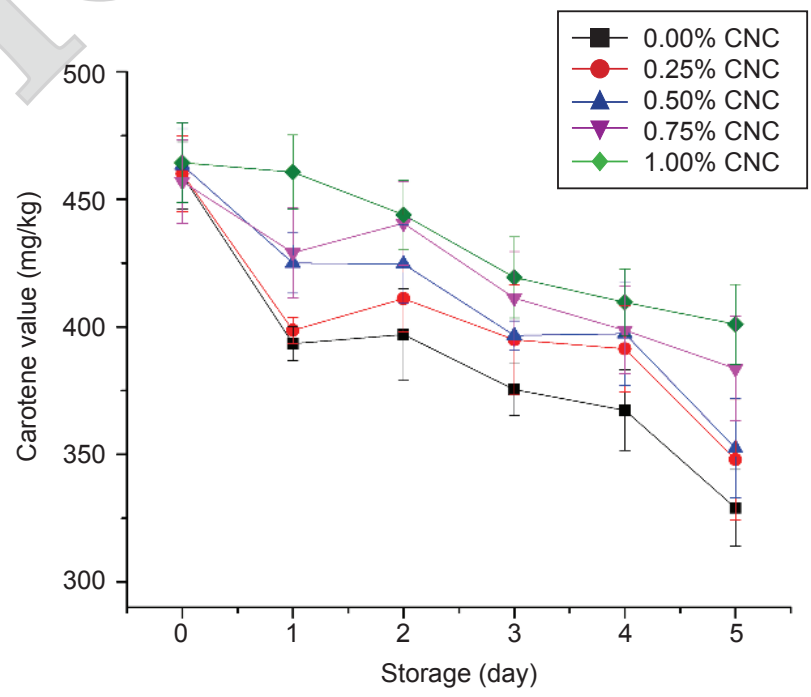

Figure 5. (a) Lipid peroxide value (PV), (b) p-anisidine value (p-AV), (c) free fatty acid (FFA) value, (d) total oxidation value (TOTOX), and (e) carotene value of $\mathrm{O} / \mathrm{W}$ emulsion $(20 / 80, v / v)$ with the aqueous phase containing $1.00 \%(w / v)$ of SC and different CNC concentrations as a function of accelerated testing at $90^{\circ} \mathrm{C}$. Data represent means ( $n=3$ ) with standard deviations (error bars). 
(a) Flocculation and coalescence due to low surface coverage $[(0.25-0.75 \%(w / v) \mathrm{CNC}]$

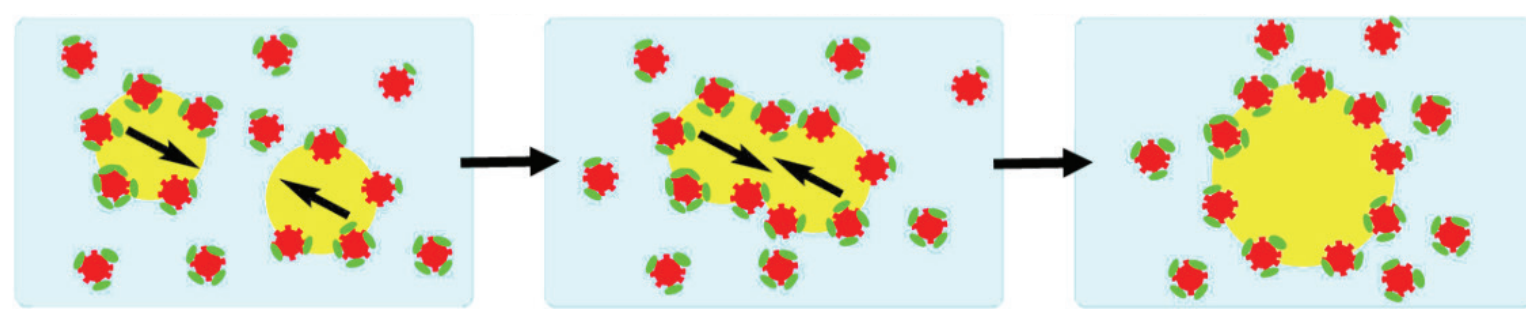

(b) Steric hindrance and electrostatic repulsion [(1\% (w/v) CNC]
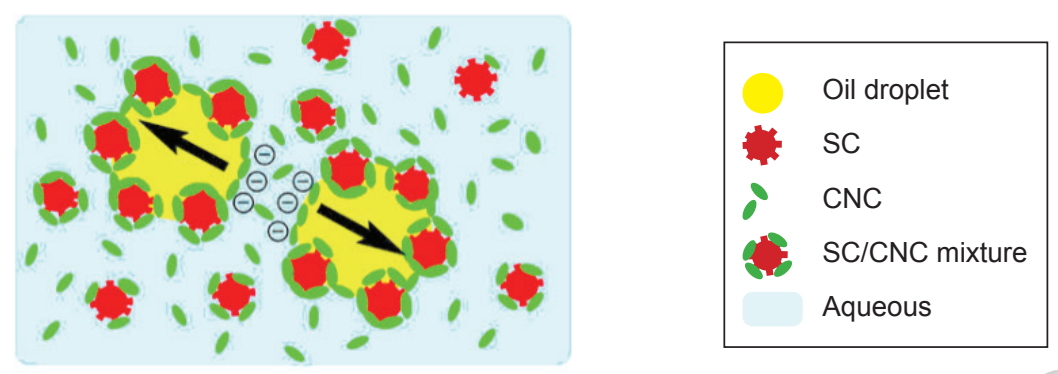

Figure 6. Schematic representation of proposed mechanism occurring (a) flocculation and coalescence (b) steric hindrance and electrostatic repulsion of $\mathrm{O} / \mathrm{W}$ emulsion $(20 / 80, v / v)$ with the aqueous phase containing $1.00 \%(w / v)$ of SC and different CNC concentrations.

\section{CONCLUSION}

This study demonstrated the preparation of stable red palm $\mathrm{O} / \mathrm{W}$ emulsions using a double biopolymer system containing SC and CNC particles. The effects of CNC concentration at a constant amount of SC on emulsion properties were investigated. The results showed that all the SC/CNC-stabilised emulsions exhibited improved physical stability, such as smaller droplet size, lower creaming index, higher surface charges, and improved oxidative stability compared to emulsions stabilised by SC alone. It was found that the mixed biopolymer-based emulsions containing $1.00 \%$ SC and $1.00 \%$ CNC were of superior stability against flocculation and coalescence during storage. The presence of negative charges around droplet surfaces also rendered the emulsions stable. Due to its antioxidant nature, the presence of CNC could inhibit the production of the first and second oxidation products of emulsions. Compared to SCstabilised alone emulsions, SC/CNC-stabilised emulsions presented lower TOTOX value, FFA value with high carotene retention. Overall, our findings presented the beneficial effects of a dual biopolymer system comprising SC and CNC in improving the physical and oxidative stability of food-grade emulsions.

\section{ACKNOWLEDGEMENT}

The authors are grateful to Sime Darby Research, Tropical Medicine and Biology Platform, School of Science and Advanced Engineering Platform,
School of Engineering, Monash University Malaysia for the financial support and sample analysis of the research.

\section{REFERENCES}

Ainie, K; Siew, W L; Tan, Y A; Noraini, I; Mohtar, Y; Tang, T S and Nuzulamri, I (2004). MPOB Test Methods - A Compendium of Test on Palm Oil Products, Palm Kernel Products, Fatty Acids, Food Related Products and Others. MPOB, Bangi.

American Oil Chemists' Society (AOCS) (1997). Official Methods and Recommended Practices of the AOCS. AOCS Press. Champaign, USA.

Berton-Carabin, C C; Ropers, M H and Genot, C (2014). Lipid oxidation in oil-in-water emulsions: Involvement of the interfacial layer. Compr. Rev. Food Sci. Food Saf., 13(5): 945-977.

Bonnie Tay, Y P and Choo, Y M (2000). Valuable minor constituents of commercial red palm olein: Carotenoids, vitamin E, ubiquinones and sterols. J. Oil Palm Res., 12: 14-24.

Cao, Y; Ai, N; True, A D and Xiong, Y L (2018). Effects of (-)-epigallocatechin-3-gallate incorporation on the physicochemical and oxidative stability of myofibrillar protein-soybean oil emulsions. Food Chem., 245: 439-445.

Chang, C and Nickerson, M T (2018). Encapsulation of omega 3-6-9 fatty acids-rich oils using protein- 
based emulsions with spray drying. J. Food Sci. Technol., 55(8): 2850-2861.

Cheetangdee, N and Benjakul, S (2015). Antioxidant activities of rice bran protein hydrolysates in bulk oil and oil-in-water emulsion. J. Sci. Food Agric., 95(7): 1461-1468.

Chen, Q H; Zheng, J; Xu, Y T; Yin, S W; Liu, F and Tang, C H (2018). Surface modification improves fabrication of pickering high internal phase emulsions stabilised by cellulose nanocrystals. Food Hydrocoll., 75: 125-130.

Chew, C L; Ab Karim, N A; Quek, W P; Wong, S K; Lee, Y Y and Chan, E S (2021). Aerobic-liquor treatment improves the quality and deep-frying performance of refined palm oil. Food Control, 126: 108072.

Chityala, P K; Khouryieh, H; Williams, K and Conte, E (2016). Effect of xanthan/enzyme-modified guar gum mixtures on the stability of whey protein isolate stabilised fish oil-in-water emulsions. Food Chem., 212: 332-340.

Clegg, P S; Tavacoli, J W and Wilde, P J (2016). One-step production of multiple emulsions: Microfluidic, polymer-stabilised and particlestabilised approaches. Soft Matter, 12(4): 998-1008.

Pereira de Abreu, D A; Paseiro Losada, P; Maroto, J and Cruz, J M (2010). Evaluation of the effectiveness of a new active packaging film containing natural antioxidants (from barley husks) that retard lipid damage in frozen Atlantic salmon (Salmo salar L.). Food Res. Int., 43(5): 1277-1282.

Ferreira, C D; da Conceição, E J L; Machado, B A S; Hermes, V S; de Oliveira Rios, A; Druzian, J I and Nunes, I L (2016). Physicochemical characterisation and oxidative stability of microencapsulated crude palm oil by spray drying. Food Bioprocess Technol., 9(1): 124-136.

Francis, M J; Glover, Z J; Yu, Q; Povey, M J and Holmes, M J (2019). Acoustic characterisation of $\mathrm{pH}$ dependant reversible micellar casein aggregation. Colloids Surf. A Physicochem. Eng. Asp., 568: 259-265.

Grishkewich, N; Mohammed, N; Tang, J and Tam, K C (2017). Recent advances in the application of cellulose nanocrystals. Curr. Opin. Colloid Interface Sci., 29: 32-45.

Guzey, D and McClements, D J (2006). Formation, stability and properties of multilayer emulsions for application in the food industry. Adv. Colloid Interface Sci., 128-130: 227-248.
Ho, K W; Ooi, C W; Mwangi, W W; Leong, W F; Tey, B T and Chan, E S (2016). Comparison of selfaggregated chitosan particles prepared with and without ultrasonication pretreatment as Pickering emulsifier. Food Hydrocoll., 52: 827-837.

Hu, H Y; Xing, L J; Hu, Y Y; Qiao, C L; Wu, T; Zhou, G H and Zhang, W G (2016). Effects of regenerated cellulose on oil-in-water emulsions stabilised by sodium caseinate. Food Hydrocoll., 52: 38-46.

Jacobsen, C; Sørensen, A D and Nielsen, N (2013). Stabilisation of omega-3 oils and enriched foods using antioxidants. Food Enrichment with Omega-3 Fatty Acids (Jacobsen, C; Nielsen, N S; Horn, A F and Sørensen, A-D M eds.). Woodhead Publishing. p. 130-149.

Jeon, T Y and Hong, J S (2014). Stabilisation of $\mathrm{O} / \mathrm{W}$ emulsion with hydrophilic/hydrophobic clay particles. Colloid Polym. Sci., 292(11): 2939-2947.

Le, T T; Saveyn, P; Hoa, H D and Van der Meeren, P (2008). Determination of heat-induced effects on the particle size distribution of casein micelles by dynamic light scattering and nanoparticle tracking analysis. Int. Dairy J., 18(12): 1090-1096.

Li, K; Woo, M W; Patel, H and Selomulya, C (2017). Enhancing the stability of protein-polysaccharides emulsions via Maillard reaction for better oil encapsulation in spray-dried powders by $\mathrm{pH}$ adjustment. Food Hydrocoll., 69: 121-131.

Liu, H; Li, Y; Diao, X; Kong, B and Liu, Q (2018). Effect of porcine bone protein hydrolysates on the emulsifying and oxidative stability of oil-in-water emulsions. Colloids Surf. A Physicochem. Eng. Asp., 538: 757-764.

Liu, L; Zhao, Q; Liu, T; Kong, J; Long, Z and Zhao, M (2012). Sodium caseinate/carboxymethylcellulose interactions at oil-water interface: Relationship to emulsion stability. Food Chem., 132(4): 1822-1829.

Lomova, M V; Sukhorukov, G B and Antipina, M N (2010). Antioxidant coating of micronsize droplets for prevention of lipid peroxidation in oil-in-water emulsion. ACS Appl. Mater. Interfaces, 2(12): 36693676.

Low, L E; Siva, S P; Ho, Y K; Chan, E S and Tey, B T (2020). Recent advances of characterisation techniques for the formation, physical properties and stability of Pickering emulsion. Adv. Colloid Interface Sci., 277: 102117.

Low, L E; Tey, B T; Ong, B H; Chan, E S and Tang, S Y (2017). Palm olein-in-water Pickering 
emulsion stabilised by $\mathrm{Fe}_{3} \mathrm{O}_{4}$-cellulose nanocrystal nanocomposites and their responses to $\mathrm{pH}$. Carbohydr. Polym., 155: 391-399.

Low, L E; Wong, S K; Tang, S Y; Chew, C L; De Silva, H A; Lee, J M V; Hoo, C H and Kenrick, K (2019). Production of highly uniform Pickering emulsions by novel high-intensity ultrasonic tubular reactor (HUTR). Ultrason. Sonochem., 54: 121-128.

Luo, Y; Teng, Z; Wang, T T Y and Wang, Q (2013). Cellular uptake and transport of zein nanoparticles: Effects of sodium caseinate. J. Agric. Food Chem., 61(31): 7621-7629.

Manoj, P; Fillery-Travis, A J; Watson, A D; Hibberd, D J and Robins, M M (1998). I. Creaming behavior. J. Colloid Interface Sci., 207(2): 283-293.

McClements, D J (2015). Food Emulsions: Principles, Practices and Techniques. $3^{\text {rd }}$ edition. CRC press.

Moigradean, D; Poiana, M A and Gogoasa, I (2012). Quality characteristics and oxidative stability of coconut oil during storage. J. Agroaliment. Processes Technol., 18(4): 272-276.

Ortiz, D G; Pochat-Bohatier, C; Cambedouzou, J; Bechelany, M and Miele, P (2020). Current trends in Pickering emulsions: Particle morphology and applications. Engineering, 6(4): 468-482.

Pindáková, L; Kašpárková, V and Bordes, R (2019). Role of protein-cellulose nanocrystal interactions in the stabilisation of emulsion. J. Colloid Interface Sci., 557: 196-206.

Qiu, C; Zhao, M; Decker, E A and McClements, D J (2015). Influence of anionic dietary fibers (xanthan gum and pectin) on oxidative stability and lipid digestibility of wheat protein-stabilised fish oil-inwater emulsion. Food Res. Int., 74: 131-139.

Song, X; Zheng, F; Ma, F; Kang, H and Ren, H (2020). The physical and oxidative stabilities of Pickering emulsion stabilised by starch particle and small molecular surfactant. Food Chem., 303: 125391.

Sukyai, P; Anongjanya, P; Bunyahwuthakul, N; Kongsin, K; Harnkarnsujarit, N; Sukatta, U; Sothornvit, R and Chollakup, R (2018). Effect of cellulose nanocrystals from sugarcane bagasse on whey protein isolate-based films. Food Res. Int., 107: 528-535.

Svagan, A J; Koch, C B; Hedenqvist, M S; Nilsson, F; Glasser, G; Baluschev, S and Andersen, M L (2016). Liquid-core nanocellulose-shell capsules with tunable oxygen permeability. Carbohydr. Polym., 136: 292-299.

Wang, P; Chen, C; Guo, H; Zhang, H; Yang, Z and Ren, F (2018). Casein gel particles as novel soft Pickering stabilisers: The emulsifying property and packing behaviour at the oil-water interface. Food Hydrocoll., 77: 689-698.

Wong, S K; Supramaniam, J; Wong, T W; Soottitantawat, A; Ruktanonchai, U R; Tey, B T and Tang, S Y (2021). Synthesis of bio-inspired cellulose nanocrystals-soy protein isolate nanoconjugate for stabilisation of oil-in-water Pickering emulsions. Carbohydr. Res., 504: 108336.

Xu, X; Liu, W; Luo, L; Liu, C and McClements, D J (2017a). Influence of anionic polysaccharides on the physical and oxidative stability of hydrolyzed rice glutelin emulsions: Impact of polysaccharide type and pH. Food Hydrocoll., 72: 185-194.

Xu, L; Yu, X; Li, M; Chen, J and Wang, X (2017b). Monitoring oxidative stability and changes in key volatile compounds in edible oils during ambient storage through HS-SPME/GC-MS. Int. J. Food Prop., 20(sup3): S2926-S2938.

Yodkaew, P; Chindapan, N and Devahastin, S (2017). Influences of superheated steam roasting and water activity control as oxidation mitigation methods on physicochemical properties, lipid oxidation and free fatty acids compositions of roasted rice. J. Food Sci., 82(1): 69-79.

Yokota, S; Kamada, K; Sugiyama, A and Kondo, T (2019). Pickering emulsion stabilisation by using amphiphilic cellulose nanofibrils prepared by aqueous counter collision. Carbohydr. Polym., 226: 115293.

Zeng, T; Wu, Z 1; Zhu, J Y; Yin, S W; Tang, C H; Wu, L Y and Yang, X Q (2017). Development of antioxidant Pickering high internal phase emulsions (HIPEs) stabilised by protein/polysaccharide hybrid particles as potential alternative for PHOs. Food Chem., 231: 122-130.

Zinoviadou, K G; Scholten, E; Moschakis, T and Biliaderis, C G (2012). Properties of emulsions stabilised by sodium caseinate-chitosan complexes. Int. Dairy J., 26(1): 94-101.

Zoppe, J O; Venditti, R A and Rojas, O J (2012). Pickering emulsions stabilised by cellulose nanocrystals grafted with thermo-responsive polymer brushes. J. Colloid Interface Sci., 369(1): 202209. 